\title{
County and Physician Variation in Benzodiazepine Prescribing to Medicare Beneficiaries by Primary Care Physicians in the USA
}

\author{
Donovan T. Maust, MD, $M S^{1,2,3}$, Lewei A. Lin, $M D^{1,2,3}$, Frederic C. Blow, $P h D^{1,2,3}$, and \\ Steven C. Marcus, PhD \\ 'Department of Psychiatry, University of Michigan, Ann Arbor, MI, USA; ${ }^{2}$ Institute for Healthcare Policy and Innovation, University of Michigan, Ann \\ Arbor, MI, USA; ${ }^{3}$ Center for Clinical Management Research, VA Ann Arbor Healthcare System, Ann Arbor, MI, USA; ${ }^{4}$ School of Social Practice and \\ Policy, University of Pennsylvania, Philadelphia, PA, USA.
}

BACKGROUND: Physicians widely prescribe benzodiazepines (BZD) despite well-recognized harms.

OBJECTIVE: To determine county and provider characteristics that predict high-intensity BZD prescribing by primary care physicians (PCPs) to Medicare beneficiaries.

DESIGN: Cross-sectional analysis of the 2015 Medicare Part D Public Use Files (PUF).

SUBJECTS: $n=122,054$ PCPs who prescribed 37.3 billion medication days.

MAIN MEASURES: Primary outcome was intensity of BZD prescribing (days prescribed/total medication days) at the county- and physician levels. PCP and county characteristics were derived from the Part D PUF, Area Health Resources Files, and County Health Rankings. Logistic regression determined the characteristics associated with high-intensity (top quartile) BZD prescribing.

KEY RESULTS: Beneficiaries were prescribed over 1.2 billion days of BZD in 2015, accounting for 2.3\% of all medication days prescribed in Part D. Top quartile counties had 3.1 times higher BZD prescribing than the lowest (3.4\% vs. $1.1 \% ; F=3293.8, \mathrm{df}=3, p<0.001$ ). Adjusting for county-level demographics and health care system characteristics (including supply of mental health providers), counties with more adults with at least some college had lower odds of high-intensity prescribing (per 5\% increase, adjusted odds ratio [AOR] 0.80, 99\% confidence interval (CI) 0.73-0.87, $p<0.001$ ), as did higher income counties (per US\$1000 increase, AOR 0.93, CI 0.91-0.95, $p<0.001)$. Top quartile PCPs prescribed at 6.5 times the rate of the bottom $(3.9 \%$ vs. $0.6 \% ; F=63,910.2$, $\mathrm{df}=3, p<0.001)$. High-intensity opioid prescribing (AOR 4.18, CI 3.90-4.48, $p<0.001$ ) was the characteristic most strongly associated with BZD prescribing. CONCLUSIONS: BZD prescribing appears to vary across counties and providers and is related to non-patient characteristics. Further work is needed to understand how such non-clinical factors drive variation.

Electronic supplementary material The online version of this article (https://doi.org/10.1007/s11606-018-4670-9) contains supplementary material, which is available to authorized users.

Received April 11, 2018

Revised June 27, 2018

Accepted September 4, 2018

Published online September 24, 2018
KEY WORDS: benzodiazepine; insomnia; anxiety; physician; primary care.

J Gen Intern Med 33(12):2180-8

DOI: $10.1007 / \mathrm{s} 11606-018-4670-9$

(C) Society of General Internal Medicine 2018

\section{INTRODUCTION}

Benzodiazepines (BZD) impair cognition ${ }^{1}$ and are associated with motor vehicle accidents, ${ }^{2}$ misuse and abuse, ${ }^{3}$ as well as falls $^{4}$ and fractures ${ }^{5}$ among older adults. After opioids, BZDs are the second-most common medication class linked with pharmaceutical overdose deaths, ${ }^{6}$ the rate of which grew $13.6 \%$ per year from 1996 to $2013 .^{7}$ The extent of BZD prescribing is high given the availability of safer, guidelinerecommended treatments like selective serotonin reuptake inhibitors ${ }^{8,9}$ and cognitive behavioral therapy, ${ }^{10,11}$ though BZDs may have a role in treatment-resistant cases of anxiety or insomnia. ${ }^{8,9,12,13}$ Surprisingly, a significant amount of prescribing - perhaps even the majority - occurs to patients without insomnia or a clearly defined mental health disorder. ${ }^{14-16}$

General medical settings are the country's primary mental health treatment setting. ${ }^{17}$ This is particularly true for older adults (i.e., $\geq 65$ years), as psychiatrists are less likely than other medical specialties to accept Medicare. ${ }^{18}$ This may help account for the fact that among older adults - who have the highest prevalence of BZD use but the lowest use of specialty mental health care $^{19}$ - just $5.6 \%$ of those prescribed a BZD receive it from a psychiatrist. ${ }^{20}$

Within primary care, the links between geographic or prescriber characteristics and BZD prescribing have been subject to little research. Variation in BZD prescribing at the physician level may indicate a lack of knowledge about or consensus regarding their appropriate use. Case and Deaton recently suggested that growth in mortality among white Americans - partially driven by drug and alcohol poisonings and suicide - reflects an epidemic of distress. ${ }^{21}$ The growing disparities in life expectancy among US counties, largely driven by county-level race and socioeconomic status, ${ }^{22}$ suggest that such distress is concentrated within particular communities. If mental health disorders are not fully driving BZD 
prescribing, more extensive BZD prescribing in socioeconomically distressed counties might suggest that this distress - rather than a clinical indication such as panic disorder - is driving potentially inappropriate prescribing.

Understanding how BZD prescribing varies across primary care settings may help design and target interventions with the greatest potential to reduce prescribing, especially given the possible reluctance of patients ${ }^{23}$ and physicians ${ }^{24}$ to broadly reduce use. To our knowledge, no prior national analysis has examined BZD prescribing at the county and physician levels. The foundation of this analysis is the 2015 Medicare Part D Public Use Files, which contain virtually $100 \%$ of all Part D claims by Medicare beneficiaries in 2015. We pair this prescribing data with physician characteristics and county information from the Area Health Resources Files and County Health Rankings to determine the county and physician characteristics associated with high-intensity BZD prescribing.

\section{METHODS}

\section{Primary Data Source}

We used the 2015 Summary and Detailed Medicare Part D Public Use Files (PUF), ${ }^{25}$ which are derived from all Medicare Part D final-action claims from stand-alone and Medicare Advantage prescription drug plans.

The Summary PUF is organized by National Provider Identifier (NPI) and includes physician zip code, gender, and credentials; select patient panel characteristics, such as age, gender, race, low-income subsidy, and hierarchical condition category (HCC; a risk-adjustment score calculated by the Centers for Medicare \& Medicaid Services [CMS]); and summary prescribing information, including total days prescribed overall and of specific medication classes, including opioids, antibiotics, and high-risk medications in the elderly. ${ }^{26}$ The Summary PUF includes information on over 57.7 billion days of prescription claims from 1.1 million prescribers; we limited this to 122,054 individual primary care physicians (PCPs), who as a group do the majority of BZD prescribing to older adults. $^{20}$

The Detailed PUF is organized by NPI and drug name: each row includes a distinct combination of NPI + drug name and the total days' supply for that medication, which we used to determine the total days of BZD prescribed by each PCP. To protect beneficiary privacy, the Detailed PUF excludes any record derived from $\leq 10$ claims (e.g., if a PCP prescribed eight claims for lorazepam, this combination of NPI + lorazepam is not reported). After redaction, the 2015 Detailed PUF includes 1.2 billion prescription claims or $86.9 \%$ of total Part D claims. ${ }^{25}$

\section{County- and Physician-Level Outcomes}

Our county-level outcome is the intensity of BZD prescribing by a county's PCPs defined as (days of BZDs prescribed by
PCPs $) \times 100 /($ days of all Part D medications prescribed by PCPs). We used the Summary PUF to determine the total medication days prescribed by each physician; their BZD days were determined from the Detailed PUF by adding up all days prescribed by each NPI for each BZD ${ }^{25}$ We derived the BZD intensity numerator and denominator by summing data for all PCPs within each zip code level and then using the U.S. Department of Housing and Urban Development zip-tocounty crosswalk to generate county-level estimates. ${ }^{27}$ The final sample for the county-level analysis included 3038 counties with claims from the 122,054 individual PCPs.

As with the county-level outcome, we defined PCP-level BZD prescribing intensity as (days of BZD prescribed) $\times 100$ / (total days of all Part $\mathrm{D}$ medications prescribed).

\section{Covariates for County-Level Analysis}

We determined county-level demographic, health care system, socioeconomic status (SES), and health status characteristics primarily from the County Health Rankings ${ }^{28}$ (CHR; a joint initiative of the University of Wisconsin Population Health Institute and the Robert Wood Johnson Foundation) and the Area Health Resources Files (AHRF). ${ }^{29}$ CHR and AHRF incorporate data elements from a variety of sources, including the American Community Survey, the Behavioral Risk Factor Surveillance System, and CMS (eTable 1).

Demographic and SES variables used included percentage of female residents, percentage of residents $\geq 65$ years, percentage of residents by race/ethnicity, percentage rural, percentage that completed any college, unemployment rate, and median income.

Health care system characteristics included primary care providers per 100,000 population, presence of a psychiatrist, federally qualified health center or community mental health center, and whether part of a county was designated a primary care or mental health provider shortage area. Finally, we used the Detailed PUF to determine the proportion of BZDs in each county prescribed by non-PCP physicians.

We used the following indicators of health status: proportion of disability-eligible Medicare beneficiaries, mean HCC, percentage reporting poor health in the past 30 days, days of poor health in the past 30 for physical or mental health reasons, binge alcohol use, and suicide rate.

\section{Covariates for Physician-Level Analysis}

We used the Summary PUF to categorize PCPs by specialty (internal medicine, family medicine, or geriatrics), MD or DO, gender, and years in practice (from the Medicare Physician Compare National Downloadable File). ${ }^{30}$

We used the opioid, antibiotic, and "high-risk medication" (i.e., inappropriate for adults $65+$ ) claim totals provided for every provider in the Summary PUF to determine highintensity prescribing for each of these three medication groups (i.e., high-intensity opioid PCP = top quartile of [opioid claims/total claims prescribed by that $\mathrm{PCP}]$ ). We also 
identified overall high-volume and high-intensity prescribers (see eTable 2 for further details).

Finally, we included the following PCP panel characteristics from the Summary PUF: patient age, HCC score, percentage of white patients, and percentage of patients receiving the Part D low-income subsidy.

\section{Analysis}

We determined total BZD claims in 2015 and then limited the data to those prescribed by PCPs, who prescribed $61.9 \%$ of all Part D BZD days. We ranked BZDs by individual medication, grouped as short- and long-acting. ${ }^{20}$ We sorted counties into quartiles by intensity of BZD prescribing and compared quartiles on the county characteristics of interest using chi-square or ANOVA tests. To determine the characteristics that predicted high-intensity BZD prescribing, we grouped the bottom three quartiles together and tested the bivariate association between county characteristic and BZD prescribing intensity using logistic regressions (dependent variable: $1=$ top quartile; $0=$ bottom three quartiles). Next, we used multivariable logistic regression to predict top quartile BZD prescribing as a combined function of county demographic, SES, and health care system characteristics. The second and final county-level model incorporated indicators of health status to test whether other markers of poor health and distress were associated with BZD prescribing intensity.

For the PCP-level analysis, first we excluded the bottom decile of overall low-volume PCPs $(n=12,368$; prescribed to a mean of 77 beneficiaries) because low-practice volume contributes to less reliable performance measurement, ${ }^{31}$ yielding $n=109,686$ for the physician-level analysis. We split PCPs into quartiles by prescribing intensity and compared characteristics of interest across quartiles. For the model predicting high-intensity BZD prescribing, we again grouped the bottom three quartiles together. We used a multilevel logistic regression to predict the odds of a PCP being a highintensity BZD prescriber. The model included PCP characteristics, patient panel characteristics, and county-level mental health treatment resources to account for local differences in availability of mental health specialty care as fixed effects, with a random effect for county. Analysis was completed in Stata 13.1 (College Station, TX). All statistical tests were twotailed with $\alpha=0.01$ given the large sample size and multiple comparisons. Because this analysis only uses de-identified, aggregated patient data, it is not subject to IRB approval by the University of Michigan Medical School IRB.

\section{RESULTS}

Medicare Part D beneficiaries were dispensed over US $\$ 374$ million worth and 1.2 billion total days of BZDs, which comprised $2.3 \%$ of all Part D medication days. PCPs prescribed over 728 million of all BZD days, accounting for $61.9 \%$ of BZD prescribing overall. Short-acting BZDs were prescribed most commonly (Table 1). On average, BZDs comprised $2.1 \%$ (standard deviation [SD] 0.9) of medications prescribed in a county (i.e., the intensity), with an interquartile range [IQR] of $1.5-2.6 \%$. States with the highest county-level prescribing were all in the South. The top five were Louisiana, Florida, West Virginia, Tennessee, and Alabama (Fig. 1).

\section{County-Level Analysis}

The highest-prescribing county quartile had a mean intensity of $3.4 \%, 3.1$ times higher than $1.1 \%$ in the low-intensity quartile $(\mathrm{df}=3, F=3293.8, p<0.001)$. High-intensity counties were largely found in Appalachia and south-central states; New York counties were almost entirely low intensity (Fig. 2). The prescribing intensity quartiles varied on most county-level demographics (Table 2), with the largest difference being that high-intensity counties were more rural. Highintensity counties had fewer primary care providers per 100,000 population and fewer had a psychiatrist. Highintensity counties had lower SES and fared more poorly on every health status indicator with the exception of binge alcohol use.

In the first regression model that included county-level demographic, SES, and health care system characteristics, higher education and higher income were associated with lower odds of high-intensity prescribing. In the final model, which also included indicators of county-level health status, education and income were no longer significant. However, most characteristics suggesting worse health status were associated with increased odds of high-intensity prescribing, including the proportion of disability-eligible Medicare beneficiaries, days of poor mental health in the past 30, and suicide rate. Higher binge drinking, however, was still associated with lower odds of high-intensity BZD prescribing in the final model.

\section{Physician-Level Analysis}

BZD prescribing intensity ranged from $0.6 \%$ (SD 0.2 ) among the bottom PCP quartile to $3.9 \%$ (SD 1.8) in the top ( $\mathrm{df}=3, F=63,910.2, p<0.001$ ), a 6.5 -fold difference (Table 3). In a multivariable model that adjusted for the local availability of mental health services, females had significantly lower odds of being high-intensity prescribers, while additional years in practice were associated with higher odds. Being a high-intensity opioid prescriber was the single factor most strongly associated with highintensity BZD prescribing, though every type of highintensity prescribing was associated with high BZD prescribing intensity, along with simply being a high-volume prescriber. An older patient panel was associated with lower odds of high-intensity BZD prescribing, while higher proportions of patients who were white or receiving a low-income subsidy were associated with increased odds of high-intensity BZD prescribing. 
Table 1 Total Benzodiazepine Prescriptions to Part D Medicare Beneficiaries by Primary Care Physicians in $2015(n=122,054)$

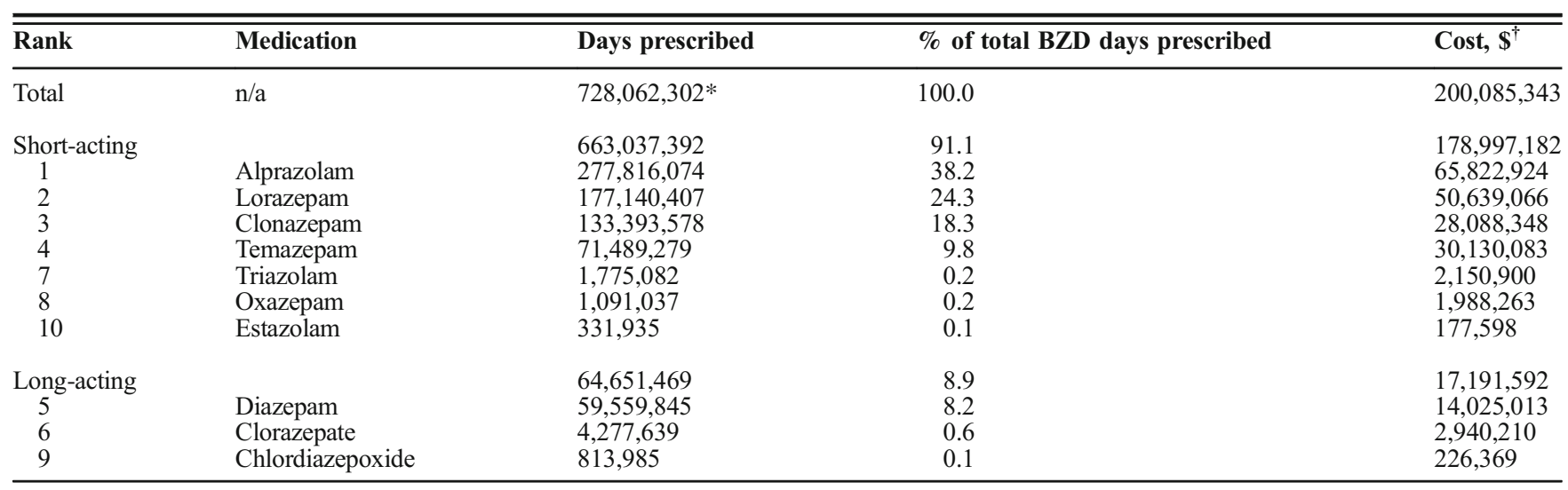

*The BZD total also includes days prescribed of clobazam, flurazepam hydrochloride, and midazolam hydrochloride, though these each accounted for fewer than $0.05 \%$ of total days prescribed and are not listed here. ${ }^{\dagger}$ This is the aggregate drug cost paid for all associated claims as reported by the Part D Public Use File, including ingredient cost, dispensing fee, and sales tax. It is based on the amounts paid by the Part D plan, Medicare beneficiary, government subsidies, and any other third-party payers ${ }^{25}$

\section{Sensitivity Analyses}

For the county-level model, we conducted sensitivity analyses using total BZD days as the numerator with two alternative denominators (eTable 3): (1) number of Medicare beneficiaries and (2) county population. For the provider-level model, we generated an alternative outcome using a denominator of Medicare beneficiaries seen (eTable 4). The association of characteristics with BZD prescribing intensity was generally consistent (i.e., the $99 \%$ CI for effect size overlapped), regardless of the denominator.

\section{DISCUSSION}

BZDs are widely prescribed to Medicare beneficiaries, and the intensity of prescribing varies markedly across US counties and individual primary care physicians. Among the top quartile of PCPs, nearly $4 \%$ of all Part D medications prescribed in 2015 were BZDs, a rate 6-fold higher than physicians in the lowest quartile.

To our knowledge, this is the first analysis to examine county-level variation in BZD prescribing. In our initial adjusted county-level model, counties with lower educational attainment and lower median income had high-intensity

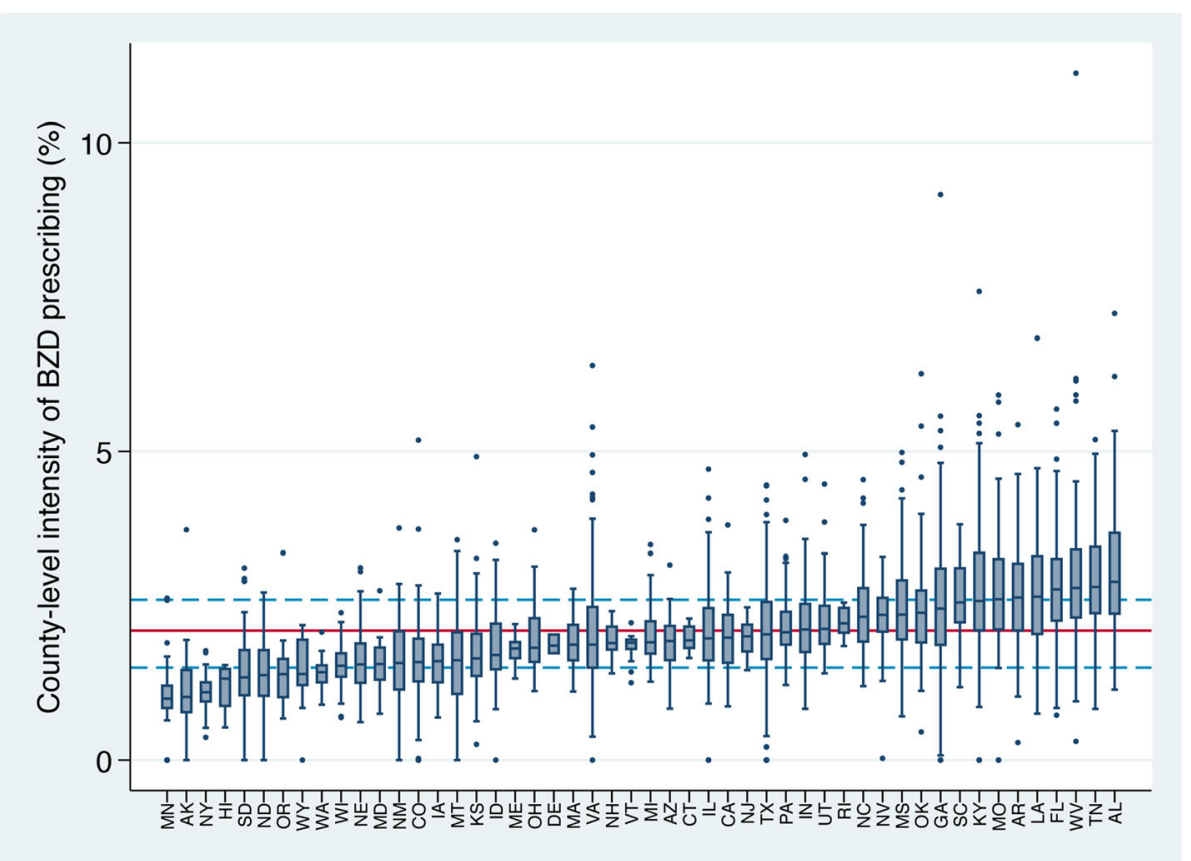

Figure 1 County-level benzodiazepine prescribing intensity by primary care physicians across 50 states and the District of Columbia $(n=3038)$. The red horizontal line is the national county-level mean (2.1\%); the dashed blue lines reflect the 25 th and 75 th percentiles $(1.5$ and $2.6 \%$, respectively). 


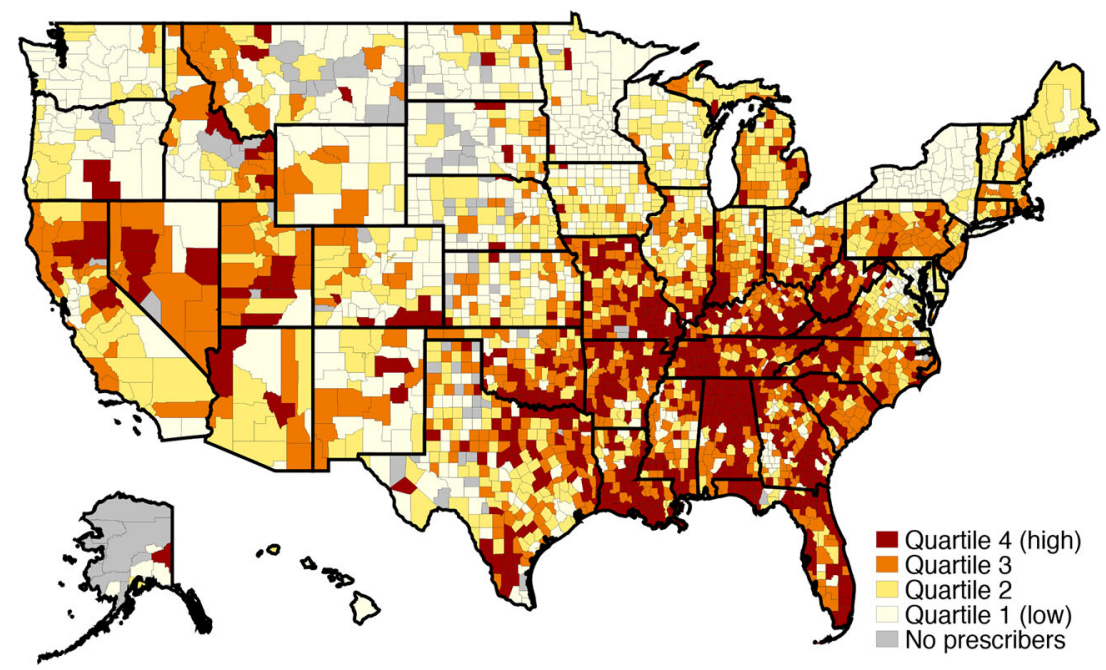

Figure 2 County-level Intensity of benzodiazepine prescribing by primary care physicians $(n=3038)$.

prescribing. In the final model, several other concerning county-level health status characteristics were associated with high-intensity BZD prescribing, including more days of poor mental health, a higher proportion of disability-eligible Medicare beneficiaries, and a higher suicide rate. Because a large amount of BZD prescribing occurs without a mental health or insomnia diagnosis, ${ }^{14,16,32,33}$ our findings fit Case and Deaton's hypothesis, with prescribing potentially in response to distress in socioeconomically disadvantaged counties. It was unexpected that binge alcohol use was higher in lowintensity BZD counties, though the prevalence of binge alcohol use is higher in high-income households. ${ }^{34}$

The high-intensity counties share a striking overlap with county opioid use..$^{35}$ The Part D PUF cannot determine whether a PCP is prescribing opioids and BZDs to the same patient. However, the fact that the same PCPs appear to be highintensity prescribers of both medications is potential cause for concern. Our findings are consistent with a recent analysis of opioid and BZD prescribing to Medicaid beneficiaries with opioid use disorders, where prescribing rates varied significantly by provider and were higher in high-poverty counties. ${ }^{36}$ Some of the socioeconomic characteristics associated with BZD prescribing intensity have also been proposed as determinants in the opioid crisis $^{37}$; it is unsurprising the same PCPs might be high-intensity prescribers of both.

A clear outlier is New York, which initiated a restrictive BZD triplicate prescription policy 30 years ago that does not permit refills: all but three counties were in the lowest intensity quartile. This cannot be because patients in New York are uniquely free from anxiety or insomnia, or that they have distress-free lives. It is most likely due to the restrictive policy in place, further suggesting that patient diagnosis is not the only factor to determine BZD prescribing. However, initiation of the New York policy also demonstrated that, in the face of pressure to reduce BZD prescribing, physicians may simply shift to even less desirable sedating medications. ${ }^{38}$
Over $90 \%$ of BZD days prescribed were for short-acting medications, such as alprazolam and lorazepam, consistent with prior work showing use of short-acting BZDs has increased. ${ }^{32}$ This may reflect providers' response to earlier findings $^{39}$ and recommendations ${ }^{40,41}$ that long-acting BZDs elevated risk of hip fracture relative to short-acting agents. However, subsequent analyses have suggested that the risk of short-acting agents is similarly high, ${ }^{5,42}$ and recent guidelines caution against all BZDs, regardless of half-life. ${ }^{43}$

The decision to prescribe a medication should depend on the presence of an underlying medical disorder. However, each physician may have their own BZD prescribing threshold and prescribing practice. One PCP characteristic associated with lower odds of high-intensity BZD prescribing was female gender. Other analyses have demonstrated that female clinicians may provider better care, ${ }^{44-46}$ though the reasons are unclear. Roter et al. have found that female physicians provide more psychosocial counseling, ${ }^{47}$ while "female primary care physicians engage in more communication that can be considered patient centered and have longer visits than their male colleagues". ${ }^{48}$ For a patient in distress, it could be that a conversation with a female physician is perceived by both patient and physician as therapeutic in itself.

The single PCP factor that most strongly predicted highintensity BZD prescribing was being a high-intensity opioid prescriber. However, being a high-intensity prescriber of antibiotics and high-risk medications for the elderly were also strongly associated. It is unclear why the fact that a PCP prescribes a lot of these medications - for unrelated conditions - would be associated with their BZD prescribing practice. However, as with the gender difference, some providers may be more comfortable using education and communication as part of treatment, which is useful whether addressing psychosocial distress or a viral upper respiratory infection.

Our analysis has several limitations. We do not have patient-level clinical data, which may account for some 
Table 2 Demographic, Healthcare System, Socioeconomic, and Health Status Characteristics Associated with County-Level Benzodiazepine Prescribing Intensity by Primary Care Physicians in $2015(n=3038)$

\begin{tabular}{|c|c|c|c|c|c|c|c|c|c|}
\hline \multirow[t]{2}{*}{ County characteristic } & \multicolumn{6}{|c|}{ BZD prescribing intensity quartile* } & \multirow[b]{2}{*}{$\begin{array}{l}\mathrm{OR}^{\dagger}(99 \% \\
\mathrm{CI})\end{array}$} & \multirow[b]{2}{*}{$\begin{array}{l}\text { Model 1 } \\
\text { AOR } \\
(99 \% \text { CI) }\end{array}$} & \multirow[b]{2}{*}{$\begin{array}{l}\text { Model } 2 \\
\text { AOR } \\
(99 \% \text { CI })\end{array}$} \\
\hline & $\begin{array}{l}\mathrm{q} 1 \\
(n=760)\end{array}$ & $\begin{array}{l}\mathrm{q} 2 \\
(n=759)\end{array}$ & $\begin{array}{l}\mathrm{q3} \\
(n=760)\end{array}$ & $\begin{array}{l}\text { low } \\
(\mathrm{q} 1-3) \\
(n=2279)\end{array}$ & $\begin{array}{l}\text { high } \\
(\mathrm{q} 4) \\
(n=759)\end{array}$ & $p$ value & & & \\
\hline $\begin{array}{l}\text { Intensity (BZD days/total } \\
\text { med days) }\end{array}$ & 1.1 & 1.8 & 2.3 & 1.7 & 3.4 & $<0.001$ & $\mathrm{n} / \mathrm{a}$ & $\mathrm{n} / \mathrm{a}$ & $\mathrm{n} / \mathrm{a}$ \\
\hline \multicolumn{10}{|l|}{ Demographic } \\
\hline Female, \% & 49.7 & 50.0 & 50.1 & 49.9 & 50.1 & $<0.001$ & \multirow{3}{*}{$\begin{array}{l}1.21 \\
(0.93-1.57) \\
1.21 \\
(1.07-1.36)^{\S}\end{array}$} & $\begin{array}{l}1.61 \\
(1.19-2.18)^{\S}\end{array}$ & \multirow{2}{*}{$\begin{array}{l}0.90 \\
(0.64-1.26) \\
1.24 \\
(0.97-1.60)\end{array}$} \\
\hline$\geq 65$ years of age, $\%$ & 17.7 & 18.0 & 17.6 & 17.7 & 18.5 & $<0.001$ & & $\begin{array}{l}0.84 \\
(0.70-1.00)\end{array}$ & \\
\hline \multicolumn{9}{|l|}{ Race, $\%$} & \\
\hline Non-Hispanic white & 75.8 & 76.5 & 76.1 & 76.1 & 79.4 & 0.001 & \multirow{5}{*}{$\begin{array}{l}1.04 \\
(1.02-1.08)^{\S} \\
1.05 \\
(1.01-1.09)^{\|} \\
0.88 \\
(0.82-0.92)^{\S} \\
0.06 \\
(0.03-0.14)^{\S} \\
1.06 \\
(1.04-1.08)^{\S}\end{array}$} & $\begin{array}{l}1.23 \\
(1.09-1.39)^{\S}\end{array}$ & \multirow{5}{*}{$\begin{array}{l}1.31 \\
(1.13-1.52)^{\S} \\
1.19 \\
(1.02-1.39)^{\|} \\
1.33 \\
(1.13-1.56)^{\S} \\
0.89 \\
(0.39-2.07) \\
0.98 \\
(0.95-1.01)\end{array}$} \\
\hline Non-Hispanic black & 6.6 & 8.5 & 10.9 & 8.6 & 10.7 & $<0.001$ & & $\begin{array}{l}1.05 \\
(0.93-1.19)\end{array}$ & \\
\hline Hispanic & 11.0 & 10.2 & 8.9 & 6.5 & 10.0 & $<0.001$ & & $\begin{array}{l}1.04 \\
(0.91-1.18)\end{array}$ & \\
\hline Asian & 2.1 & 1.6 & 1.3 & 1.7 & 0.8 & $<0.001$ & & $\begin{array}{l}0.82 \\
(0.38-1.79)\end{array}$ & \\
\hline Rural, \% & 56.5 & 53.1 & 54.4 & 54.6 & 65.8 & $<0.001$ & & $\begin{array}{l}0.97 \\
(0.94-1.00)\end{array}$ & \\
\hline \multicolumn{10}{|l|}{ Health care system } \\
\hline $\begin{array}{l}\text { Primary care providers per } \\
100,000, n\end{array}$ & 60.6 & 58.9 & 53.5 & 57.7 & 43.7 & $<0.001$ & \multirow{7}{*}{$\begin{array}{l}0.99 \\
(0.98-0.99)^{\S} \\
0.54 \\
(0.43-0.67)^{\S} \\
0.77 \\
(0.48-1.21) \\
1.22 \\
(0.98-1.52) \\
1.07 \\
(0.78-1.46) \\
1.75 \\
(1.15-2.67)^{\S} \\
0.87 \\
(0.84-0.89)^{\S}\end{array}$} & $\begin{array}{l}0.99 \\
(0.99-0.99)^{\S}\end{array}$ & \multirow{7}{*}{$\begin{array}{l}0.99 \\
(0.99-0.99)^{\|} \\
0.91 \\
(0.65-1.28) \\
1.14 \\
(0.64-2.02) \\
0.81 \\
(0.60-1.09) \\
0.73 \\
(0.48-1.11) \\
1.39 \\
(0.84-2.30) \\
0.88 \\
(0.85-0.92)^{\S}\end{array}$} \\
\hline$\geq 1$ psychiatrist (ref: 0 ) & 44.4 & 53.4 & 48.4 & 48.7 & 33.7 & $<0.001$ & & $\begin{array}{l}1.14 \\
(0.83-1.57)\end{array}$ & \\
\hline $\begin{array}{l}\geq 1 \text { community mental } \\
\text { health center (ref: } 0)\end{array}$ & 5.9 & 8.3 & 7.1 & 7.1 & 5.5 & 0.13 & & $\begin{array}{l}1.49 \\
(0.86-2.59)\end{array}$ & \\
\hline $\begin{array}{l}\geq 1 \text { federally qualified } \\
\text { health center (ref: } 0 \text { ) }\end{array}$ & 50.1 & 56.9 & 59.0 & 55.3 & 60.2 & 0.02 & & $\begin{array}{l}1.12 \\
(0.85-1.47)\end{array}$ & \\
\hline $\begin{array}{l}\text { Primary care provider } \\
\text { shortage area (ref: no) }\end{array}$ & 85.1 & 86.7 & 85.5 & 85.8 & 86.6 & 0.59 & & $\begin{array}{l}0.69 \\
(0.47-1.02)\end{array}$ & \\
\hline $\begin{array}{l}\text { Mental health provider } \\
\text { shortage area (ref: no) }\end{array}$ & 91.4 & 88.7 & 88.2 & 89.4 & 93.7 & 0.001 & & $\begin{array}{l}1.23 \\
(0.75-2.01)\end{array}$ & \\
\hline $\begin{array}{l}\% \text { of BZD days prescribed } \\
\text { by non-PCPs }\end{array}$ & 41.6 & 33.4 & 27.8 & 34.3 & 23.7 & $<0.001$ & & $\begin{array}{l}0.89 \\
(0.86-1.47)^{\S}\end{array}$ & \\
\hline \multicolumn{10}{|l|}{ Socioeconomic status } \\
\hline $\begin{array}{l}\text { Adults } 25-44 \text { with at least } \\
\text { some college, } \%\end{array}$ & 60.7 & 59.3 & 56.5 & 58.8 & 50.4 & $<0.001$ & \multirow{3}{*}{$\begin{array}{l}0.71 \\
(0.67-0.74)^{\S} \\
3.92 \\
(2.93-5.24)^{\S} \\
0.92 \\
(0.91-0.93)^{\S}\end{array}$} & $\begin{array}{l}0.80 \\
(0.73-0.87)^{\S}\end{array}$ & \multirow{3}{*}{$\begin{array}{l}0.95 \\
(0.86-1.05) \\
0.66 \\
(0.39-1.12) \\
0.98 \\
(0.96-1.01)\end{array}$} \\
\hline Unemployment, \% & 5.0 & 5.2 & 5.6 & 5.3 & 6.3 & $<0.001$ & & $\begin{array}{l}1.47 \\
(0.97-2.24)\end{array}$ & \\
\hline $\begin{array}{l}\text { Median household income, } \\
\$^{\mathbb{I I}}\end{array}$ & 52,470 & 51,600 & 48,011 & 50,694 & 42,331 & $<0.001$ & & $\begin{array}{l}0.93 \\
(0.91-0.95)^{\S}\end{array}$ & \\
\hline \multicolumn{10}{|l|}{ Health status } \\
\hline $\begin{array}{l}\text { Medicare disability- } \\
\text { eligible, } \%\end{array}$ & 17.4 & 18.5 & 20.9 & 18.9 & 25.1 & $<0.001$ & \multirow{2}{*}{$\begin{array}{l}2.11 \\
(1.92-2.33)^{\S} \\
1.53 \\
(1.36-1.73)^{\S}\end{array}$} & - & \multirow{7}{*}{$\begin{array}{l}1.69 \\
(1.39-2.06)^{\S} \\
1.49 \\
(1.22-1.81)^{\S} \\
0.65 \\
(0.36-1.17) \\
0.69 \\
(0.31-1.57) \\
4.68 \\
(2.31-9.49)^{\S} \\
0.59 \\
(0.40-0.89)^{\|} \\
1.06 \\
(1.03-1.10)^{\S}\end{array}$} \\
\hline $\mathrm{HCC}^{* *}$ & 0.91 & 0.94 & 0.95 & 0.93 & 0.97 & $<0.001$ & & - & \\
\hline $\begin{array}{l}\text { Adults reporting fair to } \\
\text { poor health, } \%\end{array}$ & 15.4 & 16.0 & 17.3 & 16.2 & 19.5 & $<0.001$ & $\begin{array}{l}1.99 \\
(1.77-2.24)^{\S}\end{array}$ & - & \\
\hline $\begin{array}{l}\text { Days of poor physical } \\
\text { health in past } 30\end{array}$ & 3.6 & 3.7 & 4.0 & 3.8 & 4.4 & $<0.001$ & $\begin{array}{l}3.59 \\
(3.01-4.27)^{\S}\end{array}$ & - & \\
\hline $\begin{array}{l}\text { Days of poor mental health } \\
\text { in past } 30\end{array}$ & 3.5 & 3.6 & 3.8 & 3.7 & 4.2 & $<0.001$ & $\begin{array}{l}6.28 \\
(4.93-8.00)^{\S}\end{array}$ & - & \\
\hline $\begin{array}{l}\text { Binge drinking in prior } \\
\text { month, } \%\end{array}$ & 18.1 & 17.3 & 16.2 & 17.2 & 14.7 & $<0.001$ & $\begin{array}{l}0.24 \\
(0.20-0.30)^{\S}\end{array}$ & - & \\
\hline Suicide rate per 100,000 & 14.1 & 13.8 & 14.4 & 14.1 & 15.9 & $<0.001$ & $\begin{array}{l}1.06 \\
(1.04-1.08)^{\S}\end{array}$ & - & \\
\hline
\end{tabular}

OR odds ratio, AOR adjusted odds ratio, CI 99\% confidence interval

*Quartiles 1-3 are presented both separately and combined. The $p$ value reflects the significance test for the ANOVA or chi-square comparison across the four quartiles. ${ }^{\dagger}$ OR represents the odds of a county being in the top BZD prescribing intensity quartile (q4) relative to the bottom three (q1-3). For characteristics reported as \%, the OR presented is for a 5\% change in the given characteristic. For example, an additional $5 \%$ of county-level female population is associated with 1.16 odds of being in the high-prescribing quartile (versus the bottom three quartiles). ${ }^{*}$ Model 1 includes county demographic, health care system, and socioeconomic characteristics. Model 2 includes all model 1 characteristics (demographic, health care system, socioeconomic) and adds health status indicators that may reflect county-level distress and poor health

$s_{p}<0.001$

$p<0.01$

"OR reflects per $\$ 1000$ increase in median income

**OR reflects per 0.1 increase in $H C C$ 
Table 3 Primary Care Physician, Prescribing, and Panel Characteristics Associated with Physician-Level Benzodiazepine Prescribing Intensity, $2015(n=109,686)$

\begin{tabular}{|c|c|c|c|c|c|c|c|c|}
\hline \multirow[t]{2}{*}{ Characteristic } & \multicolumn{6}{|c|}{ BZD prescribing intensity quartile* } & \multirow[b]{2}{*}{$\begin{array}{l}\mathrm{OR}^{\dagger}(99 \% \\
\mathrm{CI})\end{array}$} & \multirow[b]{2}{*}{$\begin{array}{l}\mathrm{AOR}^{*} \\
(99 \% \mathrm{CI})\end{array}$} \\
\hline & $\begin{array}{l}\mathrm{q1} \\
(n=27,422)\end{array}$ & $\begin{array}{l}\mathrm{q}^{2} \\
(n=27,421)\end{array}$ & $\begin{array}{l}\mathrm{q3} \\
(n=27,422)\end{array}$ & $\begin{array}{l}\text { low }(q 1-3) \\
(n=82,265)\end{array}$ & $\begin{array}{l}\operatorname{high}(\mathrm{q} 4) \\
(n=27,421)\end{array}$ & $p$ value & & \\
\hline $\begin{array}{l}\text { Intensity (BZD days/total } \\
\text { med days) }\end{array}$ & 0.6 & 1.3 & 2.1 & 1.4 & 3.9 & $<0.001$ & $\mathrm{n} / \mathrm{a}$ & $\mathrm{n} / \mathrm{a}$ \\
\hline \multicolumn{9}{|l|}{ Physician } \\
\hline Internal medicine & 46.6 & 45.2 & 44.5 & 45.4 & 41.3 & \multirow[t]{3}{*}{$<0.001$} & \multirow{3}{*}{$\begin{array}{l}\text { Ref } \\
1.12 \\
(1.08-1.17)^{\S} \\
0.65 \\
(0.52-0.81)^{\S}\end{array}$} & \multirow{3}{*}{$\begin{array}{l}\text { Ref } \\
0.99 \\
(0.94-1.05) \\
0.91 \\
(0.70-1.19)\end{array}$} \\
\hline Family medicine & 51.9 & 53.5 & 54.5 & 53.3 & 58.0 & & & \\
\hline Geriatrics & 1.5 & 1.3 & 1.0 & 1.2 & 0.7 & & & \\
\hline $\begin{array}{l}\text { License, \% } \\
\text { MD }\end{array}$ & 89.6 & 87.3 & 85.7 & 83.8 & 83.8 & \multirow{2}{*}{$<0.001$} & Ref & \multirow{2}{*}{$\begin{array}{l}\text { Ref } \\
1.25 \\
(1.17-1.34)^{\mathrm{s}}\end{array}$} \\
\hline DO & 10.4 & 12.7 & 14.3 & 12.4 & 16.2 & & $\begin{array}{l}1.25 \\
(1.19-1.33)^{\S}\end{array}$ & \\
\hline \multicolumn{9}{|l|}{ Gender, $\%$} \\
\hline Male & 60.5 & 64.3 & 67.8 & 64.2 & 73.2 & \multirow[t]{2}{*}{$<0.001$} & Ref & \multirow{3}{*}{$\begin{array}{l}\text { Ref } \\
0.70 \\
(0.65-0.75)^{\S} \\
1.31 \\
(1.28-1.34)^{\S}\end{array}$} \\
\hline Female & 39.5 & 35.7 & 32.2 & 35.8 & 26.8 & & $\begin{array}{l}0.70 \\
(0.67-0.73)^{\S}\end{array}$ & \\
\hline Time in practice, years $\|$ & 23.3 & 23.5 & 24.2 & 23.6 & 26.0 & $<0.001$ & $\begin{array}{l}1.24 \\
(1.22-1.27)^{\S}\end{array}$ & \\
\hline \multicolumn{9}{|l|}{ Prescribing ${ }^{\mathbb{I}}$} \\
\hline High-intensity opioid, \% & 12.6 & 18.2 & 24.9 & 18.6 & 44.3 & $<0.001$ & \multirow{4}{*}{$\begin{array}{l}4.79 \\
(4.57-5.02)^{\S} \\
1.54 \\
(1.48-1.61)^{\S} \\
2.81 \\
(2.68-2.94)^{\S} \\
0.27 \\
(0.26-0.29)^{\S}\end{array}$} & \multirow{4}{*}{$\begin{array}{l}4.18 \\
(3.90-4.48)^{\S} \\
1.37 \\
(1.28-1.46)^{\S} \\
2.38 \\
(2.23-2.54)^{\S} \\
0.89 \\
(0.82-0.96)^{\S}\end{array}$} \\
\hline High-intensity antibiotic, $\%$ & 20.4 & 22.5 & 25.6 & 22.8 & 31.5 & $<0.001$ & & \\
\hline $\begin{array}{l}\text { High-intensity high-risk } \\
\text { medication, } \%\end{array}$ & 13.6 & 20.0 & 27.5 & 20.3 & 38.6 & $<0.001$ & & \\
\hline $\begin{array}{l}\text { No high-intensity opioid, } \\
\text { antibiotic, or high-risk } \\
\text { medication, \% }\end{array}$ & 61.9 & 52.7 & 42.4 & 52.3 & 26.1 & $<0.001$ & & \\
\hline High-volume overall, \% & 14.7 & 23.0 & 29.7 & 22.5 & 32.6 & $<0.001$ & $\begin{array}{l}1.37 \\
(1.31-1.43)^{\S}\end{array}$ & $\begin{array}{l}1.53 \\
(1.45-1.62)^{\S}\end{array}$ \\
\hline High-intensity overall, \% & 18.5 & 23.4 & 27.2 & 23.0 & 30.9 & $<0.001$ & $\begin{array}{l}1.32 \\
(1.27-1.39)^{\S}\end{array}$ & $\begin{array}{l}1.20 \\
(1.13-1.27)^{\S}\end{array}$ \\
\hline \multicolumn{9}{|l|}{ Patient panel } \\
\hline Age, years & 72.0 & 72.4 & 72.4 & 72.2 & 71.1 & $<0.001$ & \multirow{5}{*}{$\begin{array}{l}0.95 \\
(0.94-0.95)^{\S} \\
0.97 \\
(0.96-0.98)^{\S} \\
1.07 \\
(1.06-1.08)^{\S} \\
1.03 \\
(1.03-1.04)^{\S} \\
1.00 \\
(1.00-1.01)\end{array}$} & \multirow{5}{*}{$\begin{array}{l}0.95 \\
(0.94-0.96)^{\S} \\
1.09 \\
(1.07-1.11)^{\S} \\
1.14 \\
(1.13-1.15)^{\S} \\
1.06 \\
(1.05-1.07)^{\S} \\
0.99 \\
(0.98-0.99)^{\S}\end{array}$} \\
\hline Female, $\% * *$ & 60.9 & 61.2 & 61.1 & 61.1 & 60.5 & $<0.001$ & & \\
\hline White, \%** & 69.6 & 77.1 & 80.1 & 75.6 & 79.2 & $<0.001$ & & \\
\hline $\begin{array}{l}\text { Low-income subsidy, } \\
\% * *\end{array}$ & 31.5 & 27.0 & 26.3 & 28.3 & 30.6 & $<0.001$ & & \\
\hline $\mathrm{HCC}^{\dagger \dagger}$ & 1.34 & 1.32 & 1.32 & 1.33 & 1.35 & $<0.001$ & & \\
\hline
\end{tabular}

OR odds ratio, AOR adjusted odds ratio, CI 99\% confidence interval

*Quartiles 1-3 are presented both separately and combined. The p value reflects the significance test for the ANOVA or chi-square comparison across the four quartiles. ${ }^{\dagger}$ OR represents the odds of a PCP being in the top BZD prescribing intensity quartile relative to the bottom three. ${ }^{\ddagger}$ Model is a mixedeffects regression with physician, prescribing, and panel characteristics as fixed effects, with county as a random effect. In addition, it accounts for availability of county-level mental health care treatment resources among those health care system variables in Table 2 (e.g., $\geq 1$ psychiatrist, $\geq 1$ community mental health center, mental health provider shortage area, and \% of BZD days prescribed by non-PCPS) as additional fixed effects. Excludes those PCPs missing time in practice variable ( $n=10,337$ [9.4\%]; final model $n=99,349)$

$\hat{s}_{p}<0.001$

OR reported as per additional 10 years in practice

"High-intensity" is defined as among the top quartile of physicians on the particular characteristic

**OR reported as per $5 \%$ increase

${ }^{\dagger} \mathrm{OR}$ reported per 0.1-point HCC increase

variation in physician- and county-level BZD prescribing, nor individual data on socioeconomic or demographic characteristics, which we analyzed based on county characteristics of the PCP practice location. While our analysis is a near-complete picture of BZD prescribing, because of data redaction the Medicare Public Use Files include the vast majority of - but not all — prescription claims. This means that our findings may be biased by the exclusion of PCPs that see few Medicare Part D patients or who have too few claims for a specific medication to be included in the Detailed PUF. We do not know about the dosing or chronicity of individual BZD prescriptions. Finally, we do not address prescribing by other types of prescribers - both other physician specialties as well as non-physician providers - who may vary widely in their BZD prescribing. 
County and PCP characteristics significantly predict the intensity of BZD prescribing to Medicare beneficiaries, even when accounting for availability of mental health treatment resources. Given disparities in healthy aging reported by older adults ${ }^{49}$ and the non-specific nature of BZD prescribing, it is possible that some BZD prescribing to Medicare beneficiaries is in response to distress. Our county-level findings also demonstrate significant overlap with areas of high-intensity opioid prescribing, ${ }^{35}$ while high-intensity opioid prescribing is the physician characteristic most predictive of high-intensity BZD prescribing. Given the potential adverse outcomes associated with their use - particularly in combination with opioids - it is important to consider whether this variation in BZD prescribing may be contributing to the uneven distribution of gains in or even worsening of life expectancy in counties across the USA. $^{22}$

Contributors: Only those acknowledged as authors.

Corresponding Author: Donovan T. Maust, MD, MS; Department of Psychiatry, University of Michigan, Ann Arbor, MI, USA (e-mail:maustd@umich.edu).

Funders This work was supported by the Beeson Career Development Award Program (NIA K08AG048321, the American Federation for Aging Research, The John A. Hartford Foundation, and The Atlantic Philanthropies) and NIDA 1R01DA045705.

\section{Compliance with Ethical Standards:}

Conflict of Interest: Dr. Marcus reports receiving consulting fees from Alkermes, Allergan, Sage Therapeutics, Sunovion Pharmaceuticals, and Ortho-McNeil Janssen. All remaining authors declare that they do not have a conflict of interest.

\section{REFERENCES}

1. Tannenbaum C, Paquette A, Hilmer S, Holroyd-Leduc J, Carnahan R. A systematic review of amnestic and non-amnestic mild cognitive impairment induced by anticholinergic, antihistamine, GABAergic and opioid drugs. Drugs Aging. 2012;29(8):639-58.

2. Dassanayake T, Michie P, Carter G, Jones A. Effects of benzodiazepines, antidepressants and opioids on driving: a systematic review and meta-analysis of epidemiological and experimental evidence. Drug Saf. 2011;34(2):125-56.

3. O'Brien CP. Benzodiazepine use, abuse, and dependence. J Clin Psychiatry. 2005;66(suppl 2):28-33.

4. Woolcott JC, Richardson KJ, Wiens MO, et al. Meta-analysis of the impact of 9 medication classes on falls in elderly persons. Arch Intern Med. 2009;169(21):1952-60.

5. Wang PS, Bohn RL, Glynn RJ, Mogun H, Avorn J. Hazardous benzodiazepine regimens in the elderly: effects of half-life, dosage, and duration on risk of hip fracture. Am J Psychiatry. 2001;158(6):892-8.

6. Jones CM, Mack KA, Paulozzi LJ. Pharmaceutical overdose deaths, United States, 2010. JAMA. 2013;309(7):657-9.

7. Bachhuber MA, Hennessy S, Cunningham CO, Starrels JL. Increasing benzodiazepine prescriptions and overdose mortality in the United States, 1996-2013. Am J Public Health. 2016;106(4):686-8.

8. Baldwin DS, Anderson IM, Nutt DJ, et al. Evidence-based pharmacological treatment of anxiety disorders, post-traumatic stress disorder and obsessive-compulsive disorder: a revision of the 2005 guidelines from the British Association for Psychopharmacology. J Psychopharmacol. 2014;28(5):403-39.

9. Stein MB, Craske MG. Treating Anxiety in 2017. JAMA. 2017;318:235.

10. Sateia MJ, Buysse DJ, Krystal AD, Neubauer DN, Heald JL. Clinical practice guideline for the pharmacologic treatment of chronic insomnia in adults: an American Academy of Sleep Medicine Clinical Practice Guideline. J Clin Sleep Med. 2017;13(02):307-49.

11. Morin CM, Vallières A, Guay B, et al. Cognitive behavioral therapy, singly and combined with medication, for persistent insomnia: a randomized controlled trial. JAMA. 2009;301(19):2005-15.

12. Gaseem A, Kansagara D, Forciea MA, Cooke M, Denberg TD. Management of chronic insomnia disorder in adults: a clinical practice guideline from the American College of Physicians. Ann Intern Med. 2016;165(2):125-33.

13. Buysse DJ, Rush AJ, Reynolds CF. Clinical management of insomnia disorder. JAMA. 2017;318(20):1973-4.

14. Maust DT, Kales HC, Wiechers IR, Blow FC, Olfson M. No end in sight: benzodiazepine use in older adults in the United States. J Am Geriatr Soc. 2016;64(12):2546-53.

15. Wiechers IR, Leslie DL, Rosenheck RA. Prescribing of psychotropic medications to patients without a psychiatric diagnosis. Psychiatr Serv. 2013;64(12):1243-8.

16. Simon GE, Vonkorff M, Barlow W, Pabiniak C, Wagner E. Predictors of chronic benzodiazepine use in a health maintenance organization sample. J Clin Epidemiol. 1996;49(9):1067-73.

17. Unützer J, Schoenbaum M, Druss BG, Katon WJ. Transforming mental health care at the interface with general medicine: report for the presidents commission. Psychiatr Serv. 2006;57(1):37-47.

18. Bishop TF, Seirup JK, Pincus HA, Ross JS. Population of us practicing psychiatrists declined, 2003-13, which may help explain poor access to mental health care. Health Aff (Millwood). 2016;35(7):1271-7.

19. Klap R, Unroe KT, Unutzer J. Caring for mental illness in the United States: a focus on older adults. Am J Geriatr Psychiatry. 2003;11(5):51724.

20. Olfson M, King M, Schoenbaum M. Benzodiazepine use in the United States. JAMA Psychiatry. 2015;72(2):136-42.

21. Case A, Deaton A. Rising morbidity and mortality in midlife among white non-Hispanic Americans in the 21st century. Proc Natl Acad Sci U S A. 2015;112(49): 15078-83.

22. Dwyer-Lindgren L, Bertozzi-Villa A, Stubbs RW, et al. Inequalities in Life expectancy among US counties, 1980 to 2014: temporal trends and key drivers. JAMA Intern Med. 2017;177(7):1003-11.

23. Cook JM, Biyanova T, Masci C, Coyne JC. Older patient perspectives on long-term anxiolytic benzodiazepine use and discontinuation: a qualitative study. J Gen Intern Med. 2007;22(8):1094-100.

24. Cook JM, Marshall R, Masci C, Coyne JC. Physicians' perspectives on prescribing benzodiazepines for older adults: a qualitative study. J Gen Intern Med 2007;22(3):303-7.

25. Centers for Medicare \& Medicaid Services. medicare fee-for-service provider utilization \& payment data part d prescriber public use file: a methodological overview. https://www.cms.gov/Research-Statistics-Data-and-Systems/Statistics-Trends-and-Reports/Medicare-ProviderCharge-Data/Downloads/Prescriber_Methods.pdf. Accessed July 24, 2018.

26. Center for Medicare \& Medicaid Services. Part D Drug National Summary table, CY2015. https://www.cms.gov/Research-Statistics-Data-and-Systems/Statistics-Trends-and-Reports/Medicare-Provider-Charge-Data/ PartD2015.html. Accessed July 24, 2018.

27. U.S. Department of Housing and Urban Development. HUD USPS Zip Code Crosswalk Files. https://www.huduser.gov/portal/datasets/usps crosswalk.html\#codebook. Accessed July 24, 2018.

28. Robert Wood Johnson Foundation and University of Wisconsin Population Health Institute. County Health Rankings \& Roadmaps. http://www. countyhealthrankings.org/. Accessed July 24, 2018.

29. Health Resources and Services Administration. Area Health Resources Files (AHRF): Overview. Rockville, MD. http://ahrf.hrsa.gov/overview. html. Accessed July 24, 2018.

30. Centers for Medicare \& Medicaid Services. Physician Compare Datasets. https://data.medicare.gov/data/physician-compare. Accessed July 24, 2018

31. Hofer TP, Hayward RA, Greenfield S, Wagner EH, Kaplan SH, Manning WG. The unreliability of individual physician "report cards" for assessing the costs and quality of care of a chronic disease. JAMA. 1999;281(22):2098-105.

32. Maust DT, Blow FC, Wiechers IR, Kales HC, Marcus SC. National trends in antidepressant, benzodiazepine, and other sedative-hypnotic treatment of older adults in psychiatric and primary care. J Clin Psychiatry. 2017;78(04):e363-e71

33. Wiechers IR, Kirwin PD, Rosenheck RA. Increased risk among older veterans of prescribing psychotropic medication in the absence of psychiatric diagnoses. Am J Geriatr Psychiatry. 2014;22(6):531-9. 
34. Centers for Disease Control and Prevention. Vital signs: binge drinking prevalence, frequency, and intensity among adults-United States, 2010. MMWR Morb Mortal Wkly Rep.. 2012;61(1):14.

35. Guy GP Jr, Zhang K, Bohm MK, et al. Vital signs: changes in opioid prescribing in the United States, 2006-2015. MMWR Morb Mortal Wkly Rep. 2017;66(26):697-704.

36. Stein BD, Mendelsohn J, Gordon AJ, et al. Opioid analgesic and benzodiazepine prescribing among Medicaid-enrollees with opioid use disorders: the influence of provider communities. J Addict Dis. 2017;36(1):14-22.

37. Dasgupta N, Beletsky L, Ciccarone D. Opioid crisis: no easy fix to its social and economic determinants. Am J Public Health. 2018;108(2):182-

38. Weintraub M, Singh S, Byrne L, Maharaj K, Guttmacher L. Consequences of the 1989 New York State triplicate benzodiazepine prescription regulations. JAMA. 1991;266(17):2392-7.

39. Ray WA, Griffin MR, Downey W. Benzodiazepines of long and short elimination half-life and the risk of hip fracture. JAMA. 1989;262(23):3303-7.

40. Beers MH. Explicit criteria for determining potentially inappropriate medication use by the elderly: an update. Arch Intern Med. 1997;157(14):1531-6.

41. Fick DM, Cooper JW, Wade WE, Waller JL, Maclean JR, Beers MH Updating the Beers criteria for potentially inappropriate medication use in older adults: results of a US consensus panel of experts. Arch Intern Med. 2003;163(22):2716-24.
42. Wagner AK, Zhang F, Soumerai SB, et al. Benzodiazepine use and hip fractures in the elderly: who is at greatest risk? Arch Intern Med. 2004; 164(14):1567-72.

43. By the American Geriatrics Society Beers Criteria Update Expert P. American Geriatrics Society 2015 updated beers criteria for potentially inappropriate medication use in older adults. J Am Geriatr Soc. 2015;63(11):2227-46.

44. Tsugawa Y, Jena AB, Figueroa JF, Orav E, Blumenthal DM, Jha AK. Comparison of hospital mortality and readmission rates for medicare patients treated by male vs female physicians. JAMA Intern Med. 2017;177(2):206-13.

45. Berthold H, Gouni-Berthold I, Bestehorn K, Böhm M, Krone W. Physician gender is associated with the quality of type 2 diabetes care. $\mathrm{J}$ Intern Med. 2008;264(4):340-50.

46. Baumhäkel M, Müller U, Böhm M. Influence of gender of physicians and patients on guideline-recommended treatment of chronic heart failure in a cross-sectional study. Eur J Heart Fail. 2009;11(3):299-303.

47. Roter DL, Hall JA. Physician gender and patient-centered communication: a critical review of empirical research. Annu Rev Public Health. 2004;25:497-519.

48. Roter DL, Hall JA, Aoki Y. Physician gender effects in medical communication. JAMA. 2002;288(6):756-64

49. Davis MA, Guo C, Sol K, Langa KM, Nallamothu BK. Trends and disparities in the number of self-reported healthy older adults in the United States, 2000 to 2014. JAMA Intern Med. 2017;177(11):1683-4. 